\title{
A MIGRAÇÃO DE PORTUGUESES E LUSO-ANGOLANOS PARA A AMÉRICA LATINA (1975-1977) ${ }^{1}$
}

\author{
Isabel de Souza Lima Junqueira Barreto ${ }^{2}$
}

\section{Resumo:}

Durante o ano de 1975 meio milhão de pessoas chegaram a Portugal vindas das antigas colônias africanas (Angola, Moçambique, Guiné-Bissau, São Tomé e Príncipe e Cabo Verde), predominantemente dos dois primeiros, as principais colônias lusitanas no século XX. Incapaz de acomodar esse grande volume de pessoas, assolado por grave crise econômica, Portugal solicitou auxílio. Houve negociações diplomáticas entre o país e o Comitê Intergovernamental para as Migrações Europeias (CIME), atual Organização Internacional para as Migrações (OIM). Por meio dessa instituição foram contatados países da América Latina, Brasil, Argentina e Venezuela, para que tais países recebessem parte dos migrantes que majoritariamente vinham de Angola. A grande maioria deles se instalou no Brasil. O governo criou uma força tarefa para auxiliá-los na chegada. Muitos foram auxiliados pela comunidade portuguesa. Desses, entre 80 e 90\% retornaram a Portugal nos anos 1980. Quanto aos demais países da América Latina, a Venezuela, que tem a segunda maior colônia portuguesa da região, recebeu migrantes devido ao boom de exploração petrolífera. A Argentina, onde portugueses constituem o terceiro maior grupo de migrantes, recebeu um grupo menor.

Palavras-chave: Angola. África. Descolonização. Migração. América Latina.

\begin{abstract}
:
During 1975 half million people arrived in Portugal coming from its former colonies (Angola, Mozambique, Guinea-Bissau, São Tomé and Príncipe and Cape Verde), predominantly from the first two, the major Lusitanian colonies in the $20^{\text {th }}$ century. Incapable to accommodate these great volume of people, ravaged by a serious economic crises, Portugal asked for help. There were diplomatic negotiations between the country and the Intergovernmental Committee for European Migration (ICEM), nowadays known as International Organization for Migration (IOM). Through this institution Latin American countries, such as Brazil, Venezuela and Argentina, were contacted to receive migrants who, mostly, came from Angola. The great majority of them settled in Brazil. The government created a task force to help them during their arrival. Many were helped by the Portuguese community. Among these migrants between 80 and $90 \%$ left to Portugal in the 80's. As for the other Latin American countries, Venezuela that has the second major Portuguese colony of the region, received migrants because of the petroleum exploration boom. Argentina, where Portugueses are the third major migrant group, received a small group.
\end{abstract}

Key Words: Angola. Africa. Decolonization. Migration. Latin America.

\footnotetext{
${ }^{1}$ A versão original deste artigo foi originalmente apresentada no XIII Encontro de Antropologia do MERCOSUL, Universidade Federal do Rio Grande do Sul, 22 a 25 de julho de 2019.

${ }^{2}$ Pesquisadora de Conteúdo na Empresa Municipal de Multimeios, MultiRio. Doutora em História Social pela Universidade Federal Fluminense. E-mail: isljbarreto@gmail.com
} 


\section{Introdução}

O ano era 1975. Após treze anos de guerra (1961-1974), o ano que deveria ser marcado pela transição para a independência, estabelecida para 11 de novembro, foi marcado também pelo início da guerra civil em Angola (1975-2002). O pânico tomou conta da população. A população nativa deslocava-se pelo país ou se refugiou nos países vizinhos. Os ex-colonos e os luso-angolanos, descendentes de colonos nascidos em Angola, fugiram de carro em várias direções rumo aos países vizinhos, como a Namíbia, ou em barcos e por meio de uma ponte aérea de grandes proporções. A operação envolveu toda a capacidade operacional da TAP. Devido à incapacidade de dar vazão à operação, o Estado português solicitou ajuda de outros países para evacuar a população de origem portuguesa. Responderam ao apelo português os Estados Unidos, o Brasil, a França, a Grã-Bretanha, a Itália e a Noruega, entre outros países. A participação brasileira deu-se por meio da Varig, que na época contava com uma rota para a África, Rio - Johanesburgo - Luanda - Rio.

Em meio ao caos e ao pânico, a minoria de ex-colonos e descendentes lotou os consulados do Brasil e dos Estados Unidos em Luanda solicitando visto de turistas. Entre os países do continente americano os que receberam migrantes naquela conjuntura foram o Canadá, os Estados Unidos, o Brasil, a Argentina e a Venezuela. Dentre os países da América Latina, o Brasil recebeu o maior contingente. Negociações diplomáticas envolveram a oferta de assentamento de migrantes na Amazônia boliviana, projetos para o estabelecimento de técnicos e operários industriais em Caracas e outras cidades, criação de colônias agrícolas em volta da capital venezuelana e colocação de imigrantes na região do rio Orenoco, como operários para as usinas metalúrgicas ou como agricultores, que teriam a finalidade de produzir alimentos para os operários industriais na Venezuela ${ }^{3}$, bem como projetos que não chegaram a ser executados na Argentina.

No Brasil os migrantes desembarcaram maciçamente com visto de turistas e tiveram apoio oficial do governo de Brasília que criou uma força tarefa com participação de três ministérios, Trabalho, Justiça e Relações Exteriores. O papel da força tarefa era agilizar a emissão do visto de permanência bem como a emissão da carteira de trabalho. Além do apoio governamental, havia apoio da comunidade portuguesa. A Federação das Associações Portuguesas e Luso-Brasileiras mobilizou todas as casas regionais da cidade do Rio de Janeiro, principal porta de entrada desses migrantes para dar-lhes apoio inicial. Em São Paulo foi criado

\footnotetext{
${ }^{3}$ LEITE RIBEIRO, R.F.B. R [Telegrama 2521], 6 set. de 1975, f. 2.
} 
Cadernos CERU, Série 2, Vol. 31, n. 1, jun. 2020

o Movimento de Apoio ao Emigrante Português (MAEP). Tinha como função auxiliar no recomeço da vida dos migrantes.

A migração portuguesa é uma constante na história do Brasil (RIBEIRO, 1990, 2002; GOMES, 2000). Teve seu ápice após a independência política durante a República Velha (1889-1930). A partir do pós-Segunda Guerra Mundial a migração portuguesa passou a ter como destino privilegiado as antigas colônias africanas, sobretudo Angola, a "jóia da coroa" do império, e Moçambique (CASTELO, 2007). Com o êxodo, principalmente de Angola - também chegaram migrantes de Moçambique, porém, quantitativamente, não tão significativos conforme mostra o quadro abaixo a respeito dos migrantes auxiliados pelo MAEP - a migração para o Brasil voltou a ter um ligeiro aumento por um curto período de tempo (BARRETO, 2014; DEMARTINI; CUNHA, 2005, 2006, 2008; CARDOSO, 2008). Já nos demais países da América Latina, principalmente na Argentina, ela é invisível. No caso boliviano não foram encontrados dados para referência (CARREIRAS et al., 2007; NEMIROVSKY; GONZÁLES, 2005; PADILLA, 2004; PINHO 2017; XAVIER, 2009; GOMES, 2009).

Tabela 1

Emigração portuguesa África-Brasil. Dados relativos ao processo de apoio no Brasil a emigrantes portugueses oriundos da África

\begin{tabular}{|l|c|r|c|c|c|r|}
\hline & agosto & setembro & outubro & novembro & dezembro & Total \\
\hline $\begin{array}{l}\text { Portugal } \\
\text { (África via } \\
\text { Portugal) }\end{array}$ & 205 & 260 & 240 & 246 & 224 & 1.175 \\
\hline Angola & 480 & 580 & 630 & 537 & 428 & 2.655 \\
\hline Moçambique & 85 & 115 & 130 & 99 & 62 & 491 \\
\hline Macau & 5 & 8 & 4 & 1 & - & 18 \\
\hline Timor & - & 3 & 2 & 2 & 2 & 9 \\
\hline total & 775 & 966 & 1.006 & 885 & 716 & 4.348 \\
\hline
\end{tabular}

Fonte: Voz de Portugal, 20 fev. 1976, n. 2436, p. 9. Disponível em: LOBO, Eulália M.L. Imigração Portuguesa no Brasil. São Paulo: Hucitec, 2001, p. 309.

\section{A eclosão da guerra civil, a ponte aérea e as negociações diplomáticas para assentamento de migrantes}

A guerra civil eclodiu em Angola ainda no primeiro semestre de 1975. Em maio, o Acordo de Alvor, que estabelecia as diretrizes para a transição para a independência, marcada para 11 de novembro de 1975, era letra morta. As desconfianças mútuas entre os três 
Cadernos CERU, Série 2, Vol. 31, n. 1, jun. 2020

movimentos de libertação que empreenderam a guerra de independência contra Portugal, o Movimento Popular de Libertação de Angola (MPLA), a Frente Nacional de Libertação de Angola (FNLA) e a União Nacional para a Independência Total de Angola (UNITA), tornaram impossível o bom andamento do governo conjunto, que, além de representantes dos três movimentos, contava também com representantes do governo português. Os ex-colonos tentaram participar do governo criando partidos políticos diversos, porém, os mesmos não foram reconhecidos como atores válidos para tomar parte no processo. Aqueles entre os excolonos e luso-angolanos que desejassem fazê-lo deveriam se filiar a um dos movimentos que empreenderam a luta armada contra Portugal (BARRETO, 2014).

Ao longo daquele ano a realidade da guerra que, durante treze anos, não havia atingido os centros urbanos, chegou aos mesmos levando pânico à população. Se, em um primeiro momento a queda, da ditadura do Estado Novo (1933-1974) foi bem recebida pelos ex-colonos, que esperavam permanecer em Angola, o desencadeamento dos acontecimentos frustrou seus planos. A conjuntura mudava à grande velocidade. Os movimentos de libertação não aceitavam nada diferente da independência total e irrestrita. Em junho o MPLA conquistou Luanda. Com isso, os ex-colonos começaram a deixar Angola. O ápice da saída deu-se entre os meses de setembro e novembro de 1975. No princípio, mulheres acompanhadas de seus filhos eram mandadas para Portugal pelos maridos que permaneciam em solo africano para acompanhar de perto o desenrolar dos acontecimentos. Os combates, ao longo dos meses, tomaram todo o território angolano. O medo, a insegurança, a insatisfação de viver em um país onde perderiam seus privilégios sociais levou ao êxodo da minoria de origem europeia (BARRETO, 2014).

No afã de deixar o país, todos os meios de fuga eram válidos. Em comboios em direção à Namíbia, de barco pelo oceano Atlântico ou por via aérea centenas de milhares de pessoas deixaram Angola. Na Namíbia, país fronteiriço ao sul, havia campos de refugiados nas cidades de Oshakati e Grootfrontein. A Ponte Aérea mobilizou toda a frota da TAP que não conseguia dar vazão à demanda. Dessa forma o governo português empreendeu negociações com diferentes países e com a Cruz Vermelha para a evacuação de seus cidadãos. Contribuíram para a retirada dos ex-colonos e de luso-angolanos países como o Brasil, os Estados Unidos, a França, a Grã-Bretanha, a Noruega e a antiga União Soviética. O Brasil participou por meio da VARIG, que tinha uma rota para o continente africano, Rio - Johanesburgo - Luanda - Rio ${ }^{4}$. Aqueles que eram evacuados pela TAP na Ponte Aérea e pela Cruz Vermelha tinham Portugal

\footnotetext{
${ }^{4}$ PIRES, H.T. Transportes aéreos e marítimos Brasil - Angola, DTC/90, Memorandum para o Sr. Chefe do Departamento Econômico, 2 maio 1975, 3 f.. Secretaria de Estado das Relações Exteriores, Seção de Correspondência Especial, Arquivo Histórico do Itamaraty, Ministério das Relações Exteriores, Brasília, DF.
} 
como destino. Já os que compraram passagens aéreas pela Varig vieram para o Rio de Janeiro. Carlos e sua família chegaram em um avião da Varig no dia 23 de junho de 1975. Seus pais não desejavam voltar para Portugal onde tinham deixado para trás uma dura realidade:

(...) ele não queria voltar pra Portugal, (...) voltar pra lá pra fazer o quê? Pra fazer o quê? Pra voltar pro moinho? Não tinha esse propósito, se ele saiu de lá pra melhorar ele ia voltar pra lá pra quê? Como a gente, como ele tinha os recursos nós viemos pro Brasil. Por quê? Por que ele escolheu o Brasil? De novo pela facilidade da língua, né? Como em Angola também, né? Aqui, ele já tinha três irmãos (Entrevista com Carlos, Rio de Janeiro, 25 de fevereiro de 2012).

Os que desembarcaram em Portugal, encontraram uma conjuntura muito difícil na chegada. O país estava um caos. Em meio a um processo revolucionário era assolado por uma gravíssima crise econômica. Se contarmos todos os que chegaram a Portugal vindos da África, designados pejorativamente de "retornados", cerca de meio milhão de pessoas desembarcaram no país sem condições mínimas de recebê-las.

Ao chegarem foram hostilizados pela população. Da sua perspectiva a maior parte dos que desembarcaram não aceitavam a alcunha de "retornados". Muitos deles nasceram na África e nunca tinha estado na antiga metrópole. No caso dos luso-africanos que chegaram, havia ainda outra questão: por terem nascido na África eram pejorativamente tratados como "brancos de segunda”, ou seja, brancos de segunda classe, cidadãos de segunda categoria.

Os primeiros governos portugueses e o próprio povo português excluiu, discriminaram os oriundos das colônias chamando-os de "retornados", um apelido pejorativo, acusando-os de estarem roubando deles a oportunidade de trabalho. Compreende-se esta reação já que Portugal é um país pequeno, de 10 milhões de habitantes, que teve dificuldades de absorver de repente 1 milhão e meio de pessoas (entrevista com Henrique, Rio de Janeiro, 17 de junho de 2009).

Estigmatizados, recebiam auxílio estatal por meio do Instituto de Auxílio aos Retornados Nacionais (IARN).

Eles chegaram ali, eles não tinham para onde ir. Então, o Estado é que tinha que manter aquele povo, que seria dar alimento, higiene, saúde, onde é que ia colocá-los e tal. Tudo isso que eu tinha que fazer. Eu estava até nas praças fazendo esse levantamento. Eu ia para algumas comunidades menores fazendo o, digamos, o encaixe, contatando famílias, me lembro do meu pai falar que tinha uma família assim, assim, não sei aonde para nós irmos ver se a família ia receber ou não ou se ele ficava às custas do Estado. Então foi esse trabalho que eu só fiz um ano porque depois larguei para poder acompanhar o marido ao exterior (Entrevista com Fernanda - Montes Claros, 13 de outubro de 2012).

Se "retornados" era uma alcunha pejorativa, também não se pode chamar tais pessoas de refugiados. Sendo cidadãos portugueses, mesmo os nascidos nas antigas colônias, pois eram 
Cadernos CERU, Série 2, Vol. 31, n. 1, jun. 2020

consideradas "Províncias Ultramarinas" ${ }^{5}$ não eram reconhecidos pela Organização das Nações Unidas, mais precisamente seu órgão voltado para refugiados, o Alto Comissariado das Nações Unidas para os Refugiados (ACNUR) e pela Cruz Vermelha como refugiados. Como classificar aqueles que, após a descolonização da África e da Ásia, mudaram-se para a Europa? Outros países, além de Portugal, enfrentaram a questão, França, Grã-Bretanha, Holanda, Bélgica. Tais grupos tinham características semelhantes às de imigrantes ou refugiados, tais como, haviam deixado as antigas colônias de repente, no fim caótico de uma ordem política específica, sem a possibilidade de retorno, muitos migraram para um lugar onde nunca haviam estado. Uma vez chegados à antiga metrópole, tiveram que aprender todo um novo estilo de vida, tiveram que se adaptar a um novo território e um novo clima. Tiveram que criar novos laços sociais, aprender novas formas de se comportar e mudar de carreira (SMITH, 2003; BUETTNER, 2016).

Ao estudar esse grupo de pessoas, Andrea L. Smith (2003) as chama de migrantes da descolonização. Segundo a autora, pelo largo uso dos conceitos de "imigrante" e "repatriado", usados acriticamente na academia, os migrantes da descolonização eram dissociados da literatura mais ampla sobre imigração europeia. O uso do termo "repatriados" para fazer referência a esse grupo era largamente feito pelos discursos oficial e legal nas antigas metrópoles. Tal uso persiste ainda hoje. Do ponto de vista governamental, o uso de tal termo era eficiente. Ao serem assim classificados, os recém-chegados podiam ser auxiliados por agências governamentais voltadas para auxílio a cidadãos repatriados. Tais órgãos tinham a seu dispor um orçamento cuja função era auxiliar no reassentamento de tais indivíduos. O termo "repatriado", entretanto, é insuficiente, pois, a realidade desse grupo era mais complexa. Um grande número desses recém-chegados se sentia tão pouco em casa que voltaram a migrar.

Uma das razões pelas quais o uso do termo "refugiados" é inadequado quando se analisa esse grupo é o fato de serem legalmente cidadãos do Estado para o qual estavam "retornando". Embora tenham precisado passar por um período de adaptação como mostrado acima, esse fato é fundamental para diferenciar um grupo do outro. A situação do refugiado é diversa porque ele deixa o Estado onde nasceu por motivo de guerra civil ou perseguições de motivação variada, como religiosa, política ou étnica. Com sua liberdade e segurança ameaçadas e sofrendo perseguições deixaram seu país de origem para buscar refúgio em outros estados. Como bem define o ACNUR na Convenção relativa ao estatuto de refugiado de 1951:

Que, em consequência de acontecimentos ocorridos antes de $1^{\circ}$ de janeiro de 1951, e receando com razão ser perseguida em virtude da sua raça, religião,

\footnotetext{
${ }^{5}$ Termo que passou a designar as antigas colônias portuguesas em 1951. Essa mudança fez parte de uma nova política ultramarina cujo objetivo era fazer frente às críticas recebidas internacionalmente por Portugal em uma conjuntura marcada pela Descolonização da África e da Ásia.
} 
Cadernos CERU, Série 2, Vol. 31, n. 1, jun. 2020

nacionalidade, filiação em certo grupo social ou das suas opiniões políticas, se encontre fora do país de que tem a nacionalidade e não possa ou, em virtude daquele receio, não queira pedir a proteção daquele país; ou que, se não tiver nacionalidade e estiver fora do país no qual tinha a sua residência habitual após aqueles acontecimentos, não possa ou, em virtude do dito receio, a ele não queira voltar. (ACNUR apud MOREIRA, 2005, p. 61).

Em 1967, por conta de novos acontecimentos no cenário internacional, entre eles a descolonização da África, foi elaborado o Protocolo sobre o Estatuto dos Refugiados.

Este buscou pôr fim à chamada "reserva temporal" da Convenção, a qual estabelecia que só seriam reconhecidos como refugiados aqueles que tinham receio de serem perseguidos "em consequência dos acontecimentos ocorridos antes de $1^{\circ}$ de janeiro de 1951. (MOREIRA, 2005, p. 61-62).

Em 1984 o conceito de refugiado sofreu uma nova atualização. Devido aos conflitos armados e golpes militares ocorridos em diferentes países latino americanos foi aprovada a Declaração de Cartagena. Este documento ampliou a definição do conceito de refugiado. Tal definição incluiu no conceito indivíduos que deixaram seus países devido ao fato de que sua vida, segurança ou liberdade foram ameaçadas por violência generalizada (MOREIRA, 2005).

Há três soluções possíveis quando se trata de deslocamentos forçados: a repatriação voluntária, a integração local e o reassentamento ou envio a um terceiro país (MOREIRA, 2005). Outra razão pela qual se deve diferenciar os dois grupos de migrantes, no caso angolano, é a oposição do MPLA à saída em massa da minoria de origem portuguesa, pois, eles eram a parcela da população com conhecimento técnico para gestão do Estado. Dos demais movimentos, a UNITA tinha um discurso de reconhecimento dessa minoria populacional. $\mathrm{O}$ que ambos os movimentos não garantiam era a manutenção de seus privilégios. A saída em massa foi, então, uma opção. Não se pode dizer que foram expulsos, ao contrário da memória coletiva criada pelo grupo.

No caso dos migrantes da descolonização, vindos, sobretudo, de Angola, deixaram Portugal em busca de países com melhores perspectivas de vida. Como o país passava por grave crise econômica e política, aqueles que não conseguiram um emprego, preenchendo vagas deixadas por cidadãos que nunca residiram fora de Portugal e migraram por questões políticas, pois se opunham ao processo revolucionário que se iniciou em 25 de abril de 1974, voltaram a migrar.

Uma organização independente do governo, a Fraternidade Ultramarina, tinha contatos com a Federação das Associações Portuguesas e Luso-Brasileiras para auxílio àqueles que manifestavam desejo de migrar para o Brasil. Além do Brasil, espalharam-se por países como o Canadá, os Estados Unidos, a Argentina, a Venezuela e a Austrália. Esse foi o caso dos migrantes que majoritariamente deixaram Angola. Na Europa podemos destacar a França. Aqueles que haviam deixado Moçambique se dividiram, majoritariamente em dois destinos, 
Portugal e África do Sul. O governo português engajou-se em negociações bilaterais e se tornou membro do antigo Comitê Intergovernamental para as Migrações Europeias (CIME), atual Organização Internacional das Migrações (OIM) para resolver a questão dos migrantes da descolonização.

Um representante do CIME, Raymond Rodie, fez frequentes visitas à embaixada brasileira em Lisboa para negociar com o governo no sentido de o Brasil receber uma parcela desses migrantes ${ }^{6}$. Além disso, Raul Leite Ribeiro, diplomata brasileiro, enviado especial a Angola para acompanhar a conjuntura local, solicitou ao Ministro das Relações Exteriores, Antônio Francisco Azeredo da Silveira, que encaminhasse ao ex-presidente Ernesto Geisel um pedido para a criação de uma força tarefa. Tal pedido foi aprovado em agosto de $1975^{7}$. Por diretriz do governo, tal força tarefa deveria atender aos que já estivessem em solo brasileiro, pois o governo não desejava criar atritos com Portugal e Angola, que perdiam mão de obra qualificada devido ao processo revolucionário e à guerra civil respectivamente.

\section{Breves considerações sobre o trabalho de campo}

O trabalho de campo da pesquisa feita em nível de doutorado teve dois momentos. Um primeiro foi feito em arquivos e o segundo, na tessitura da rede que levou aos interlocutores ouvidos na pesquisa. Tecer essa rede de interlocutores foi difícil. $\mathrm{O}$ grupo em questão, ao contrário de outros, está disperso, não conta com instituições culturais próprias e não frequenta as instituições culturais da comunidade portuguesa. Suas memórias da vida na África e do êxodo são relembradas na esfera privada. Os migrantes transmitem suas memórias no âmbito familiar e em reuniões de grupos de amigos. Dessa forma, a memória da vivência em Angola é um fator gerador de identidade coletiva e de pertencimento, tal como apontou Pollack (1989, 1992). Assim, achá-los foi um trabalho custoso. Uma vez encontrados, devido a fatores como desconfianças e mágoas relativas a esse passado traumático, foi difícil convencê-los a aceitar participar da pesquisa. Roberto Cardoso de Oliveira (1996), ao abordar a importância do olhar, do ouvir e do escrever no fazer etnográfico lembra que

A caminhada da pesquisa é sempre difícil, sujeita a muitas quedas... É nesse ímpeto de conhecer que o ouvir, complementando o olhar, participa das mesmas precondições deste último, na medida em que está preparado para eliminar todos os ruídos que the pareçam insignificantes (...)" (OLIVEIRA, 1996, p. 18-19).

\footnotetext{
${ }^{6}$ DA FONTOURA, C.A., [telegrama 423], 13 fev. 1975, Lisboa [para] Ministério das Relações Exteriores, Brasília, 2 f. CIME. Emigração portuguesa para o Brasil, fl. 1, Série Brasil-Portugal, Telegramas Confidenciais, Coordenação-Geral de Documentação Diplomática (CDO), Seção de Arquivo Histórico, Arquivo Histórico do Itamaraty, Ministério das Relações Exteriores, Brasília D.F.).

${ }^{7}$ SILVEIRA. A.F. A da. Imigração Portuguesa. Coordenação dos serviços federais de visto, registro, legalização de permanência e encaminhamento à colocação, 21 de agosto de 1975, f.1, Centro de Pesquisa e Documentação de História Contemporânea do Brasil, CPDOC/FGV, RJ: AAS Emre rb 74.05.23, III-18 A1.
} 
Devido a questões de fundo legal e ético, a identidade dos participantes foi preservada. Todos os informantes aqui citados são referenciados com pseudônimos. Ao exercitar o olhar e o ouvir tal como ponderado acima, a etapa das entrevistas foi feita de forma livre, ou seja, após um período inicial com perguntas previamente formuladas, que inibiram muitos dos contatados, optou-se por conduzir as mesmas no formato de relatos de histórias de vida com foco no momento da saída de Angola e na chegada ao Brasil. Como lembra Cardoso de Oliveira, existe uma diferença entre o mundo do pesquisador e o mundo do interlocutor, que faz com que haja necessidade de que as perguntas sejam formuladas com cuidado. Ao todo foram ouvidos dezenove informantes. $\mathrm{O}$ olhar e o ouvir permitiram perceber o quanto o assunto é difícil de ser abordado, espinhoso ainda hoje.

Sendo uma pesquisa feita em nível de doutorado originalmente em História, mas com uma interlocução constante com a Antropologia, o saber antropológico sobre a relação antropólogo(a) / grupo social estudado foi importante. A resistência do grupo focal estudado e, a meu ver, o interesse maior em seguir com a própria vida, em vivenciar o presente e o fato de essas memórias serem dolorosas, fizeram com que não fosse possível que os interlocutores assumissem o papel dinâmico e não se estabeleceram as condições para um efetivo "diálogo", conforme aponta ainda Roberto Cardoso de Oliveira (1996).

\section{O Brasil como destino}

O Brasil foi pioneiro na regulamentação da proteção aos refugiados. Foi o primeiro país da América do Sul a aprovar a Convenção de 1951, em 1960. Em 1972 aderiu ao Protocolo de 1967. Foi também o primeiro país a elaborar uma lei específica sobre refugiados, Lei Federal 9.474/97. O país também adotou a definição ampliada de refugiado, em 1989, apesar de não ter assinado a Declaração de Cartagena de 1984. Moreira (2005) lembra que, por ter aderido à Convenção de 1951, o país tinha uma "reserva geográfica" com relação a refugiados, ou seja, só aceitava refugiados de origem europeia. A decisão de conceder estada provisória a não europeus só foi tomada em 1977, quando o ACNUR iniciou sua missão no Brasil.

São variados os motivos que levaram à escolha do Brasil como destino. A língua comum, o governo ditatorial, a existência de familiares que aqui já viviam, como foi o caso de Alice, e o momento econômico. Naquele momento o êxodo de ex-colônias e luso-africanos bem como a guerra civil em Angola eram largamente noticiados nos jornais. Houve auxílio até mesmo de pessoas desconhecidas, tal é o caso de Paulo e Bianca, que antes de optarem pelo Brasil pensaram em se estabelecerem na Espanha. $\mathrm{O}$ apartamento em que foram morar assim que chegaram pertencia ao médico com quem Paulo fez seus exames logo que chegou. Durante 
a consulta, o médico indagou a razão dos exames. Após ouvir a história de Paulo e que este voltaria para Portugal para buscar a esposa e o filho, ofereceu um apartamento seu, que estava vazio, em Copacabana, para aluguel.

(...) porque eu cheguei aqui em maio/abril de 77. Aí eu tinha familiares aqui, que já estavam aqui no Brasil, tinha três tios, tinha primos, tinha tudo aqui no Brasil, já estavam aqui no Brasil. Tinha o irmão da minha mãe, tinha mais três tias da família do meu pai, tinha aqui. Eu tinha aqui o irmão da minha mãe, que eu me correspondia com ele. (entrevista com Alice, Rio de Janeiro, 31 de março de 2011).

(...), mas você não tem casa nem apartamento, não vai alugar nada? Só quando chegar? Eu falei vou ficar num hotel baratinho (...) ele disse "não, você vai ficar num apartamento meu (...) aqui está meu cartão e o endereço (...)" (entrevista com Paulo, Rio de Janeiro, 17 de setembro de 2011).

Além da força tarefa, formada por funcionários de três ministérios, Justiça, Trabalho e Relações Exteriores, cujo objetivo era emitir em tempo o mais curto possível o visto de residência e a carteira de trabalho Modelo 19, que possibilita a estrangeiros trabalhar no Brasil, a Federação das Associações Portuguesas e Luso-Brasileiras, órgão central da comunidade portuguesa no Brasil, com sede no Rio de Janeiro, fez grandes esforços para auxiliar os migrantes a conseguir um emprego e a partir daí recomeçarem suas vidas. A ela coube todo o processo após o encerramento da Força Tarefa. Em São Paulo, também ligado à comunidade portuguesa, foi criado o Movimento de Auxílio ao Emigrante Português (MAEP). Os migrantes portugueses tinham ainda facilidades legais devido a acordos bilaterais. Em 1970 foi assinado o Acordo de Previdência Social / Segurança Social. Em 1972 Brasil e Portugal assinaram a Convenção de Direitos e Deveres (CARREIRAS et alii, 2007).

A Federação das Associações Portuguesas e Luso-Brasileiras contava com representantes no Aeroporto do Galeão, onde desembarcavam os migrantes. Era trabalho deles ensinar-lhes como chegar às diferentes Casas Regionais que os acolhiam ao chegar, caso não tivessem recursos próprios ou residências de familiares onde pudessem se instalar.

Ricardo e Glaucia também receberam apoio dessa estrutura. Ao chegarem ao aeroporto do Galeão, no dia 30 de outubro de 1975, foram instruídos a pegar um táxi e se dirigirem ao Clube Vila da Feira, na Tijuca. De lá foram encaminhados para outra instituição, um clube recreativo, chamado Banda Lusitana, localizado no Riachuelo. Ali foram recebidos em meio a outros migrantes que já se encontravam na cidade. (BARRETO, 2014, p. 172)

A comunidade portuguesa tinha laços profundos com o Estado Novo português (19331974) (DÁVILA, 2010). Para seus membros não havia a distinção "brancos de segunda", para segregar aqueles que nasciam nas antigas colônias africanas. Todos eram tratados como portugueses, indistintamente do lugar onde nasceram. Muitos dos que receberam auxílio das casas regionais ficaram abrigados nelas por um período. Além de abrigo recebiam ajuda 
Cadernos CERU, Série 2, Vol. 31, n. 1, jun. 2020

financeira e eram encaminhados para empregos, inclusive fora da cidade do Rio de Janeiro. Tais migrantes chegaram majoritariamente com visto de turistas. Ao chegarem, para conseguirem tirar a carteira de trabalho M-19 precisaram fazer baterias de exames, custeados, também, pela Federação das Associações Portuguesas e Luso-Brasileiras e pelo MAEP, no caso dos que foram residir em São Paulo (BARRETO, 2014).

No Rio de Janeiro, quem não teve abrigo nas casas regionais, mas recebeu algum tipo de ajuda do grupo de trabalho criado pela Federação das Associações Portuguesas e LusoBrasileiras, estabeleceu residência em diferentes bairros por toda a cidade (BARRETO, 2014).

Pelo fato de o país ter também sido uma ex-colônia portuguesa e ter uma relação diplomática com Portugal e o MPLA, partido que conquistou Luanda em julho de 1975 e governa o país até os dias atuais, na época um partido alinhado ideologicamente ao comunismo, o êxodo da minoria de origem europeia residente na África, sobretudo em Angola, causava comoção na opinião pública carioca.

Pela análise da documentação encontrada na sede da Federação das Associações Portuguesas e Luso-Brasileiras é possível perceber que o ápice do atendimento aos migrantes se deu em janeiro de 1976. A Ponte Aérea, que evacuou a minoria de origem portuguesa, foi encerrada em novembro de 1975. A chegada em aviões da Varig com a passagem comprada com os próprios recursos era apenas um dos meios de saída. Assim sendo, o Brasil não era a primeira opção de destino de grande parte dos migrantes. Em geral, o Brasil era o segundo destino e em alguns casos não foi o destino definitivo, pois houve quem tenha migrado novamente por não ter se adaptado. Entre aqueles que aqui fixaram residência a grande maioria, entre $80 \%$ e $90 \%$, migrou para Portugal durante a década de 1980, quando o "milagre econômico" chegou ao fim e Portugal entrou para a União Europeia.

\section{A migração portuguesa para a Argentina e Venezuela}

Além do Brasil, Venezuela e Argentina são os países da América Latina com as comunidades de imigrantes portugueses mais significativas. Na Venezuela calcula-se que residam por volta de 500 mil portugueses (GOMES, 2009). Na Argentina os portugueses representam a terceira maior comunidade imigrante. Ficam atrás de espanhóis e italianos (CARREIRAS et alii, 2007). A presença portuguesa na Venezuela data da época da chegada dos europeus à América. Estudiosos apontam que a primeira comunidade de imigrantes portugueses só se instalou de fato no século XVII.

No século XX, com a comercialização do primeiro poço de petróleo, em 1914, pela Carabian Petrolium Company, houve a terceira onda migratória significativa para o país que contava com espanhóis, italianos e portugueses. Na história da Venezuela pode-se falar em um 
Cadernos CERU, Série 2, Vol. 31, n. 1, jun. 2020

verdadeiro boom de migrantes entre 1947 e 1957 (GOMES, 2009). António de Abreu Xavier (2009), ao analisar a historiografia da imigração portuguesa para a Venezuela, divide-a em quatro períodos, da Lei de imigração de 1831 até 1935, 1935-1949, a chamada fase dos imigrantes com “estatuto jurídico", 1948-1983, período de Portas Abertas, e, por fim, o período que o autor chama de "a crise dos anos concludentes", que se iniciou ainda em 1974. Essa fase prolongou-se até a década de 1980. Uma análise dos censos populacionais indica que houve uma diminuição da população portuguesa em Caracas desde 1950. Se, em 1950, 70,2\% do total da comunidade portuguesa residia na capital, em 1961 a porcentagem correspondia a 55,8\%, em 1971 a $52,1 \%$ e em 1980 a 40,6\%.

O auge da exploração de petróleo ocorreu exatamente na década de 1970; a partir de 7374 a migração, que tinha começado a estagnar em 1958, foi revigorada. A maior parte era de origem latino-americana, porém, chegaram muitos portugueses devido à grave crise econômica instalada em Portugal após a queda do Estado Novo (1933-1974) em 25 de abril de 1974 (GOMES, 2009). A instalação de sucessivos governos provisórios de esquerda e a crise levou quem nunca viveu na África a deixar Portugal e muitos dos "retornados" a migrar para um segundo destino.

No que tange à imigração para a Argentina e de uma maneira mais ampla para a região platina, ela é invisível. São poucos os trabalhos acadêmicos que investigam a questão. O maior fluxo de imigrantes portugueses chegou à Argentina na década de 1920. A política migratória desse país era liberal. Dando prosseguimento às políticas migratórias definidas pela Constituição de 1853, garantiu aos imigrantes direitos civis fundamentais, tais como: liberdade de profissão, associação, religião e movimento, posteriormente consagradas na lei de migração de 1876. Tal política migratória oficial foi abandonada em 1936. É pratica corrente nos estudos sobre migração para a Argentina a defesa de que o país se beneficiou do programa de migração subsidiada para o Brasil, pois, nas primeiras décadas do século XX, a reemigração do Brasil para a Argentina foi algo habitual. (CARREIRAS et alii, 2007).

Os dados estatísticos oficiais tornam possível delinear três grandes períodos migratórios para a região platina ao longo do século XX. O primeiro deles foi uma extensão das tendências do século XIX e terminou na década de 1930. O segundo começou logo após o fim da Segunda Guerra Mundial e termina em meados da década de 1960. O último desses grandes períodos seguiu-se à Revolução dos Cravos (CARREIRAS et alii, 2007). Sobre esse último período os autores não podiam ser mais claros:

Por seu turno, o terceiro período, relativo à segunda metade dos anos 70 , refere-se a um aumento ligeiro e episódico da emigração portuguesa, 
Cadernos CERU, Série 2, Vol. 31, n. 1, jun. 2020

sobretudo em relação ao Brasil, e reflete a conjugação de dois fenômenos: a busca de asilo político por parte dos exilados do anterior regime e a procura de novos horizontes por parte dos que deixavam a África após a descolonização. (CARREIRAS et alii, 2007, p. 60).

A maior parte dos estudos sobre movimento migratório de Portugal para a Bacia do Prata tem a década de 1950 como recorte temporal inicial ou final. Tal fato se explica por ser esse o ano da criação da Junta Nacional de Emigração, órgão que centralizou a informação estatística. Entre 1950 e 1969 emigraram 989.558 cidadãos portugueses. Desses 31,4\% tiveram como destino o Brasil, 7,4\% se dirigiram à Venezuela e apenas 1,3\% tiveram como destino a Argentina. A maior parte dos imigrantes se estabeleceu na capital Buenos Aires e em seus arredores (CARREIRAS et alii, 2007).

\section{Conclusão}

O fluxo migratório de portugueses para o Brasil é inegavelmente o mais significativo quando se analisa a migração lusa para a América Latina. Os laços históricos entre ambos faziam do Brasil um dos lugares preferenciais para estabelecerem residência fora de Portugal. A relação entre Brasil e Portugal é, tradicionalmente, de proximidade. Durante anos Brasília endossou a política colonialista de Lisboa. Tal apoio só foi rompido na presidência de Ernesto Geisel (1974-1979). Com a política externa intitulada Pragmatismo Responsável o governo reconheceu o direito das antigas colônias portuguesas à autodeterminação. O Brasil reconheceu o governo angolano logo após a independência em 11 de novembro de 1975 (DÁVILA, 2010; SPEKTOR, 2010). O fato de o governo ter reconhecido a liderança do MPLA não impediu que dezenas de milhares de pessoas escolhessem o Brasil como destino.

Não foram conseguidas evidências do aparato de apoio a esses migrantes tanto na Argentina quanto na Venezuela nem do quantitativo de migrantes recebido por ambos os países. Por conta disso, este artigo se baseia em uma discussão bibliografica. Em solo brasileiro a criação da força-tarefa e o apoio da comunidade portuguesa foram providências para que muitos conseguissem se estabelecer. A rede de contatos estabelecida teve dimensões nacionais. Ofertas de emprego chegavam à sede da Federação das Associações Portuguesas e Luso-Brasileiras, no Rio de Janeiro, de diferentes partes do país (BARRETO, 2014). Em São Paulo o MAEP teve funções similares. A oferta de trabalho fora do eixo Rio - São Paulo evitava um inchaço populacional nas duas maiores cidades do país. Assim sendo, embora o Rio de Janeiro tenha sido a porta de entrada dos migrantes, os que não migraram novamente se espalharam pelo país. Na década de 1980, com o esgotamento do "milagre econômico", muitos migraram novamente. Entre 80 e 90\% deixaram o Brasil e se instalaram em Portugal, que, em 1986, passou a fazer parte da União Europeia (BARRETO, 2014; VENÂNCIO, 2000). Para parcela significativa dos 
Cadernos CERU, Série 2, Vol. 31, n. 1, jun. 2020

migrantes da descolonização, portanto, o estabelecimento no Brasil durou enquanto o "milagre econômico" não havia se esgotado.

\section{Bibliografia}

BARRETO, Isabel S.L.J. Migrantes da descolonização: portugueses e luso-angolanos no Brasil (1974-1977). 2014. 257 f. Tese (Doutorado em História) - Departamento de História, Universidade Federal Fluminense, Niterói.

BUETTNER, Elizabeth. Europe after Empire: Decolonization, Society, and Culture. Cambridge: Cambridge University Press, 2016.

CARDOSO, Claudia Raquel Espinha. Diáspora e Regresso: os imigrantes luso-angolanos no Brasil. 2008. 245 f. Dissertação (Mestrado em Sociologia) - Departamento de Sociologia, Universidade de São Paulo, São Paulo.

CARREIRAS, Helena et alii. Do fado ao tango: A emigração portuguesa para a Região Platina. Sociologia, Problemas e Práticas, Oeiras, n. 54, p. 49-73, maio 2007.

CASTELO, Claudia. Passagens para África: o povoamento de Angola e Moçambique com Naturais da Metrópole (1920-1974). Porto: Afrontamento, 2007.

DEMARTINI, Zeila de B. F. Reconstruindo identidades múltiplas: imigrantes portugueses e luso-africanos em São Paulo, Athenea Digital, v. 10, p. 137-153, 2006.

DEMARTINI, Zeila de B. F; CUNHA, Daniel de Oliveira. Os colonos da África Portuguesa sob o regime colonial e seu deslocamento para o Brasil no pós-independência, Cadernos CERU, São Paulo, série 2, v. 19, n.1, p. 121-137, junho 2008.

DEMARTINI, Zeila de B. F; DOPPENSCHMIT, Ellen. Desafios da pesquisa com fluxos migratórios recentes: portugueses e luso-africanos em São Paulo. Cadernos CERU, São Paulo, série 2, v. 16, n.16, p. 41-54, 2005.

DÁVILA, Jerry. Hotel Trópico: Brazil and the challenge of African Decolonization, 19501980. Durham, NC: Duke University Press, 2010.

GOMES, Angela de Castro. Histórias de imigrantes e de imigração no Rio de Janeiro. $1^{\mathrm{a}}$ ed. Rio de Janeiro: 7 Letras, 2000.

GOMES, Nancy. Os portugueses na Venezuela. Relações Internacionais, Lisboa, n. 24, p. 8392, $\quad 2009.2$ Disponível em: http://www.scielo.mec.pt/scielo.php?script=sci_arttext\&pid=S1645-

91992009000400010\&lng=pt\&nrm=iso. Acesso em: 13 jun. 2019.

MOREIRA, Julia Bertino. A problemática dos refugiados na América Latina e no Brasil. Cadernos PROLAM/USP, v. 4, n. 7, p. 57-76, 1 dez. 2005. Disponível em: http://www.revistas.usp.br/prolam/article/view/81791. Acesso em: 12 dez. 2019.

OLIVEIRA, Roberto Cardoso de. O trabalho do antropólogo: olhar, ouvir, escrever. Revista de Antropologia, v. 39, n. 1, p. 13-37, 6 jun. 1996. Disponível em: https://www.revistas.usp.br/ra/article/viewFile/111579/109656. Acesso em: 12 dez. 2019.

PINHO, Filipa. Migrações locais, tanto na origem como no destino. Entrevista a Marcelo Borges. Observatório da Emigração, Lisboa, 13 mai. 2009, revista para publicação em 
Cadernos CERU, Série 2, Vol. 31, n. 1, jun. 2020

dezembro de 2017. Disponível em: http://observatorioemigracao.pt/np4/4715.html. Acesso em: 29 abr. 2019.

POLLACK, Michael. Memória, Esquecimento, Silêncio. Estudos Históricos, Rio de Janeiro, vol.2, n.3, p. 3-15, $1989 . \quad$ Disponível em: http://bibliotecadigital.fgv.br/ojs/index.php/reh/article/view/2278/1417. Acesso em: 10 dez. 2019.

POLLACK, Michael. Memória e identidade social. Estudos Históricos, Rio de Janeiro, vol.5, n.10, p. 200-212, $1992 . \quad$ Disponível http://bibliotecadigital.fgv.br/ojs/index.php/reh/article/view/1941/1080. Acesso em: 10 dez. 2019.

RIBEIRO, Gladys Sabina. Mata Galegos: os portugueses e os conflitos de trabalho na República Velha. 1ª ed. São Paulo: Brasiliense, 1990.

RIBEIRO, Gladys Sabina. A liberdade em construção: identidade nacional e conflitos antilusitanos no Primeiro Reinado. 1 $^{\mathrm{a}}$. ed. Rio de Janeiro: Relume-Dumará, 2002.

SMITH, Andrea. L. Europe's invisible migrants. Amsterdam: Amsterdam University Press, 2003.

SPEKTOR, Matias. Azeredo da Silveira: um depoimento. Rio de Janeiro: Fundação Getúlio Vargas, 2010.

VENÂNCIO, Renato Pinto. Presença portuguesa de colonizadores a imigrantes. In: INSTITUTO BRASILEIRO DE GEOGRAFIA E ESTATÍSICA. Brasil: 500 anos de povoamento. Rio de Janeiro, 2000. Disponível em: https://biblioteca.ibge.gov.br/visualizacao/livros/liv6687.pdf. Acesso em: 10 dez. 2019.

XAVIER; António de Abreu. A comunidade portuguesa na Venezuela. Uma cronologia da sua presença contemporânea, in PADILLA, Beatriz; XAVIER, Maria (Org.). Revista Migrações Número Temático Migrações entre Portugal e América Latina, out. 2009, n. ${ }^{\circ}$ 5, Lisboa: ACIDI, p. $171-184,2009.2$ Disponível em: https://www.om.acm.gov.pt/documents/58428/183863/Migr5_Sec2_Art1.pdf/0e82ea7c-93204c32-9748-248c3bed444b. Acesso em: 12 dez. 2019. 